\title{
INVESTIGATION OF BEHAVIOR OF INTERIOR STEEL CONNECTIONS WITH OPENINGS IN BEAM WEB AND FLANGE UNDER MONOTONIC LOADING
}

\author{
Dan-Dan Yan ${ }^{1}$, Bai-Li Zhou ${ }^{2}$, Xin Guo ${ }^{1}$, Fang Lai $^{2}$, Xi Wei ${ }^{2}$, Yi-Peng Xu ${ }^{3, *}$, \\ Mehdi Esfandi Sarafraz ${ }^{4}$ and Maryam Jahanian ${ }^{5, *}$ \\ ${ }^{1}$ School of Energy and Power Engineering, XiHua University, Chengdu, Sichuan, 610039, China \\ ${ }^{2}$ School of Civil and Environmental Engineering, Xihua University, Chengdu, Sichuan, 610039, China \\ ${ }^{3}$ School of Mathematical Sciences, Tiangong University, Tianjin, 300387, China \\ ${ }^{4}$ Department of Civil Engineering, Islamic Azad University, West Tehran Branch, Tehran, Iran \\ ${ }^{5}$ MSc graduate of Structural Engineering, University of Tabriz, Tabriz, Iran \\ *(Corresponding author: E-mail: xu.yipeng90@gmail.com; mjahanian454@gmail.com)
}

\section{A B S T RA C T}

Connections are considered to be one of the most prominent components of steel moment frames and have received studious attention in recent years. The core problem of welded connections is premature brittle fracture of weld in the critical beam-to-column connection region. Within the framework of this issue, various approaches have been proposed to solve the mentioned problem. Intentional weakening of the beam web or flange is in line with the purpose of leading the plastic hinge away from the column face, hence, increasing the ductility. The aim of this research is to investigate the behavior of interior connections subjected to monotonic lateral loading in case of presence of openings in beam web or flange. To do so, an ordinary fully welded rigid connection, reduced beam section, reduced web section, and drilled flange connection models are simulated numerically, utilizing finite element software, ANSYS. The results indicate that scrupulous selection of opening sizes are of great importance to fulfill the desired outcome which is avoiding the brittle failure of connections. Furthermore, the use of drilled flange, reduced beam section, or reduced web section connection satisfy the expected performance and it is proposed to use them according to practicability, architectural and economic considerations as well as site conditions. Shear deformation and local buckling is observed in reduced web section connections while in drilled flange connections, stress concentration around the opening is critical.
A R T I C LE H IS T O RY

$\begin{array}{ll}\text { Received: } & \text { 21 June } 2020 \\ \text { Revised: } & \text { 31 March } 2021 \\ \text { Accepted: } & \text { 4 April } 2021\end{array}$

\section{K E Y W O R D S}

Interior connection;

Monotonic loading;

RWS;

RBS;

DF;

Steel moment frame

\section{Introduction}

The premature failure of steel structures due to connection damages, induced by various loadings, has received studious attention leading to the development of beam-to-column connection design processes and revision of different codes in recent years. Consequently, enhancing the structural ductility is the issue that still continues to evoke interest among researchers since the regulations emphasize the urge to design ductile systems. Intentional weakening of beam parts, strengthening the connection or utilizing dissipative elements are among commonly discussed approaches of relocating the plastic hinge away from the column face, hence, increasing the structural ductility, which is consonant with the formation of plastic hinge.

Prequalified steel moment connections described in ACI 358 [1] for SMF and IMF systems are categorized into 10 groups, among which reduced beam section (RBS) connection is a type of connection in which intentional weakening of a part of the beam flange is employed to obtain the desirable performance of beam-to-column connections. Consequently, AISC design codes have imposed some regulations on the design principles of RBS connections. However, the other types of connections are within the group in which strengthening the connection is based on added members including end-plates, steel brackets, plates, etc. Many studies have been published on utilizing RBS connections in steel moment frames [2-9]. Yet, according to [10], one of the major drawbacks to adopting the RBS connections are the limited range of beam and column dimensions in tests. Despite the fact that RBS connections are among the robust connections to be employed in steel moment frames, they experience stiffness degradation as well as loss of moment capacity [5,11-15]. Furthermore, stress concentration due to flange cut fabrication in site is a disadvantage for the seismic performance of RBS connections [16]. Based on some researches, designing RBS connections in conformance to AISC code in case of utilizing IPE sections with large dimensions appears to be insufficient, hence, stiffeners must be provided [17].

In terms of web reduction, limited number of codes including [18-20] have deemed attenuating beam web as a means of improving connection behavior, and there exist limited guidelines on steel frames with perforations in beam web. However, various opening shapes except for rectangular and circular ones are not covered in the afore-mentioned codes. In this regard, other opening shapes including elliptical-shaped, hexagon-shaped, etc. have been investigated by
[21-26] and other researches.

DF (drilled flange) connections are not covered in design codes such as [1, 10, 27-29]. Accordingly, neither regulations nor design guidance are suggested on DF connections, hence, utilizing DF connections instead of RBS ones are in their early stages. Despite the fact that fabrication of DF connections is easier than RBS ones, they perform slightly weaker [16] or nearly similar to the RBS connections [30]. However, there is still considerable uncertainty regarding the performance of DF connections. In this regard, some of the researches have approved the desired performance of DF connections in which these connections are capable of satisfying [29] AISC 341-16 requirements for rigid connections [31-34]. Hence, DF connections are deemed a sough-after substitute fo $\mathrm{r}$ RBS connections.

Many studies have investigated the behavior of connections [35-39]; also, the behavior of prefabricated beam-to-column connections were studied by many researchers [40-42] among which [40] utilized short post-tensioned prestressed strands to prevent on-site aerial tensions. Furthermore, the connection of $\mathrm{H}$-Shaped steel beam to box columns with flange plate connection was scrutinized by [43]. The behaviour of the TS semi-rigid connections were investigated through utilizing both experiments and numerical simulations by [44-45]; etc. The assessment of performance of joints between steel beam and LSWL-C columns was performed numerically and through experimental tests by [46]; among most recent researches conducted on connections, [47] used folded axillary plates, which are located at the outer side of the beam-end flanges, to improve the behavior of fully welded connection.

Various approaches have been put forward to lead the plastic hinge away from the column face through intentionally attenuating a part of the beam, among which, many attempts have been made with the purpose of improving the connection behavior through cutting of the beam flange [12, 15-16, 48-57]. Plumier [58] was the first to introduce trapezoidal beam flange cuts. Much work on the potential cut profiles of RBS connection was carried out by [11, 59-62], yet the radius cut revealed the appropriate seismic performance in comparison with other cut configurations [11,63]. Furthermore, ameliorating the behavior of RBS connections are the topic of many studies in terms of buckling which leads to an early strength degradation [64-66]. The first investigation on double reduced beam section was carried out by [57], in which two adjacent radius cuts was implemented in beam flange named as DRBS, and 
concluded that implementing the second cut leads to maximum equivalent plastic strain index reduction as well as delaying the local buckling. Investigating the behavior of RBS connections through numerical or experimental studies in the recent years are conducted by many researchers among which [67-76] can be mentioned. Fanaie et al. [69] pointed to a method in which a mathematical approach in conjunction with principles of structural analysis is employed in order to acquire the drift as well as changes in stiffness of stories in frames with RBS connections. Meng et al. [77] introduced a novel RBS connection with V-shaped reinforcing plate which improved the seismic performance of RBS connections. Moreover, the use of RBS-free and RBS-based systems in moment frames in tall buildings under earthquake excitations were scrutinized by [78]. Sensitivity study on the effect of beam slope angle as well as different design factors, including material or geometry, on the cyclic behavior of RBS connections in terms of initial stiffness, rupture index, plasticity index, moment capacity, yield moment, hysteretic energy dissipation, and strength degradation rate was performed by [79]. Results indicated the significance of the slope angle and beam depth in the response of the RBS connections.

Reduced beam web connections in which an opening is implemented in beam web has been widely investigated by many researchers [22, 24-25, 80-103]. Geol and Itani [104-105] drew the attention of researchers to reducing the beam web as a way of achieving desired performance of moment frames. The possibility of using the connections with reduced beam web was investigated by [88]. In this regard, a more recent evidence reveals that RWS connections are a desirable replacement for RBS connections in terms of story drifts and strength [106]. Furthermore, issues regarding the energy dissipation of RWS connections are addressed by [22, 95]. Detailed examination of influential parameters including opening size, location, etc. was undertaken by many researchers $[81,85-86]$, leading to the conclusion that scrupulous selection of opening dimension, shape and location is essential in order to obtain the favorable frame behavior. Various shapes of openings in RWS connections is further explored by [21-26]. Also, the capability of RWS models to reach higher story drifts (six percent) was evaluated by [82-83] both in experimental and numerical ways. The behavior of RWS connections via numerical or experimental studies in the recent years are assessed by many researchers among which [107] developed a novel RWS connection with vertical slits; [108] investigated the RWS connection with an elliptic opening in the web; [109] evaluated the cyclic performance of an eight-story welded moment frame with elliptical-shaped RWS and compared it to the conventional RBS connections; Yu and Li [110] evaluated the steel frames with RWS connections and WFP connections using the probabilistic seismic demand analysis and seismic capability analysis; Lin et al. [111] investigated the behavior of RWS in progressive collapse under critical column removal scenario, the results demonstrated the capability of the mentioned connections in terms of rotational capacity; Erfani et al. [112] studied the lateral load carrying behavior of steel moment resisting frames with reduced web beam sections and propounded an algorithm to select appropriate opening size; Bi et al. [113] scrutinized the castellated beam-to-column connections with four regular hexagonal web openings under cyclic loading with and without floor slab, the results indicated the importance of the space between web openings, and depth-to-thickness ratio of the web. Moreover, due to the limitations imposed on beam span-to-depth ratio in different codes which result in the impossibility of the use of short beams in some of the prequalified rigid connections, Hoseinzadeh Asl and Jahanian [114] investigated using web opening located at the mid-span of the deep steel beams in rigid connections in order to lead the plastic hinge away from the column face.

Utilizing drilled flange moment resisting connections is another approach to overcome the problem of weld brittle failure in the beam-to-column connections which is studied by many researchers and is almost in its early stages [17, 31-34, 115-117], among which the optimum algorithm of drilled holes in order to achieve desired performance of structure is proposed by [34, 116-117]; in this regard, initial suggestion of design algorithm for drilled flange connections as well their behavior evaluation under seismic load was performed by [118]. Evaluation of seismic performance of DF connections was reported by [119], leading to the conclusion that DF connections are capable of exhibiting desired behavior. In their 2019 study, [30] used IDA analysis method in order to investigate the seismic performance of special moment resisting frames, the results revealed that DF connections performed similar to RBS connections in case of low-rise buildings, while in high-rise buildings, DF connections demonstrated a more sought-after behavior with $43 \%$ higher seismic capacity. Among recent studies, conducted experimentally or numerically, on DF connections, the investigation of rigid connection of drilled beam to CFT columns with external stiffeners is performed by [120]; Vaidian et al. [121] evaluated the effect of different connections on the behavior of steel moment frames including RBS, DF, and DFCV connections, based on the results, DFCV connections (diamond-shaped holes) performed better than the other DF connections; the assessment of the effect of different connections, DF connections included, on the behavior of steel moment frames is performed by [122]; the results obtained in the research performed by [123] showed that clockwise pattern holes drilled in the beam flange are desirable in terms of flexibility, reduction of bending stresses, and transferring the plastic hinge away from the column face. Moreover, the investigation of the arrangement, type, and number of holes in DF connections was assessed by [124] in which it was concluded that the mentioned parameters are of great significance in the ductility, stress concentration, and preventing the brittle failure of the DF connections; [125] investigated different configurations of connections among which CDF c onnection (with combined circular hole and notches) performed better in terms of damage index, and equivalent plastic strain.

It is well-documented that pre-Northridge connections failed to resist the applied loads despite being in conformance with the existing building codes during earthquakes [10]. The afore-mentioned issue piqued interest among researches to utilize two main approaches in order to enhance the structure safety whether through strengthening the connection [96, 126-128] or weakening a part of the beam [48-125]. In terms of reducing a part of the beam, cutting the beam flange or web reduction has been widely evaluated in recent years [22-24, 56, 67-79, 88, 93-99, 127, 129]. Although comparing the behavior of interior connections with voids in beam web or flange has received numerous attention, there exists a significant ambiguity regarding the behavior of frames with web or flange cuts since cutting a part of the beam alters the force transfer from the beam to the column $[95,129]$ and parameters affecting the strength of the frame such as opening area, shape, use of stiffeners, etc., are of great significance in the behavior, resistance, energy dissipation capacity, and failure mode of the connections[2, 23-25, 114]. Hence, numerous studies have been conducted on steel connections including Reduced Beam Section (RBS)[64-79], Reduced Web Section (RWS) [80-114], Drilled Flange Connection (DFC) [115-125], and many design codes and standards [1, 10, 18-20, 27-29] employed the introduced connections as an engineered connections. Since each connection has advantages and disadvantage, e.g. limited range of beam and column dimensions in tests, stiffness degradation, loss of moment capacity, and stress concentration are among major downsides of RBS connections; limited guidelines and codes, limited shapes of openings, and loss of strength are among drawbacks of RWS connections, while absence of regulations or design guidelines, and in some cases equal or weaker performance of DF connections compared to RBS ones are considered as weaknesses of DF connections, the present study aims to evaluate the effect of different interior connections on the behavior of steel moment frames. It must be noted that connections are classified from different perspectives e.g. from the behavioral, dissipated energy capacity, modes of failure point of view. However, rotational capacity of the connections is among connection features for which there exists no proper way, and accurate estimation of the mentioned features play a significant role in the structural design of different frames and connections. In the present study, an interior connection is utilized to investigate the behavior of the connection in case of presence of openings in beam web or flange, in this regard, models with openings solely implemented in beam web or flange (RBS, RWS, and DF connections) has been investigated under monotonically increasing lateral displacement conditions with varying connection parameters like length and width of openings, and a fully welded rigid connection is simulated as a reference model. Finally, a comparative analysis is made to understand the performance of different connections under imposed monotonic loading in terms of initial stiffness, rotational capacity, resistance, and stress distribution.

\section{Modeling}

In order to investigate the performance of interior connection subjected to lateral loading, Finite element models are utilized. The numerical models are categorized into four groups, including the interior connections with fully welded rigid connection, RBS connections, interior connections with opening in beam web, and interior connections with voids in beam flange. The beam-to-column connection is deemed as a welded connection due to its vulnerability to brittle failure.

Since the location of plastic hinge formation is an influential parameter in avoiding the brittle failure of column, the spacing between the location of plastic hinge and the column face is proposed to be at least equal to the half of the beam depth [27].

Table 1 presents the properties of A992 steel, used in FE simulation, which is adopted from the coupon tests done by [130]. The weld material is assumed to have the same properties as steel base material. Stress- strain curves of the adopted A992 steel is illustrated in Fig. 1. Material nonlinearities were accounted for using a multilinear kinematic rate independent hardening rule. 
This option uses the Besseling model also called the sublayer or overlay model (Zienkiewicz) to characterize the material behavior [131]. In order to predict the yielding of the material, the Von-Mises yield criterion was used in the current paper.

Table 1

Steel properties

\begin{tabular}{|c|c|c|c|c|c|c|}
\hline \multirow[b]{2}{*}{ Material } & & \multirow{2}{*}{$\begin{array}{c}\text { Young } \\
\text { modulus } \\
(\mathrm{GPa})\end{array}$} & \multicolumn{2}{|c|}{ Yield point } & \multicolumn{2}{|c|}{ Ultimate point } \\
\hline & & & $\begin{array}{l}\text { Stress } \\
(\mathrm{MPa})\end{array}$ & Strain & $\begin{array}{l}\text { Stress } \\
(\mathrm{MPa}) \\
\end{array}$ & Strain \\
\hline \multirow{2}{*}{ A992 Steel } & Flange & 203 & 444 & 0.0042 & 577 & 0.1381 \\
\hline & Web & 202 & 409 & 0.0148 & 573 & 0.1555 \\
\hline
\end{tabular}
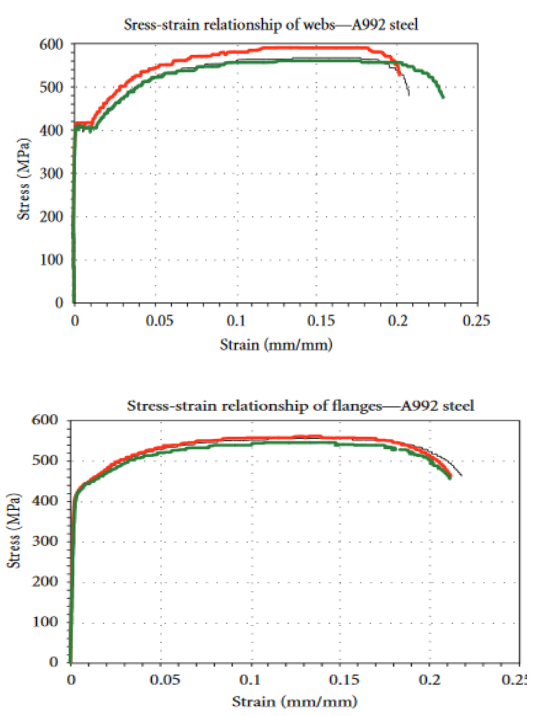

Fig. 1 Stress-strain curves of A992 steel [116]

The software package used to analyze the models was ANSYS; the FE models are comprised of a quadrilateral four-node element with six degrees of freedom per node (three rotations and three translations) which is known as SHELL181 in the ANSYS element library. SHELL181 is suitable for analyzing thin to moderately-thick shell structures [131]. Material plasticity, large deflection, and large strain nonlinearities are of the characteristics of the mentioned element. Furthermore, accurate estimations of displacements and stresses can be provided by shell elements, while according to [132-134], the utilization of the solid elements results in inaccurate prediction of the dissipated energy. Sensitivity mesh analysis was performed in order to optimize the run time, and finer mesh with mesh size $1.5 \mathrm{~cm}$ was adopted for critical areas such as connection region and the vicinity of openings while coarser mesh with mesh size $4.5 \mathrm{~cm}$ was used for the rest. Geometrical and material nonlinearities were taken into account.

In order to model the interior connection, inflection points are considered at the mid-span as well as mid-height of the column. In this regard, pinned supports is considered at the lower part of the column, besides, roller support condition is applied at the both right and left half-beam ends. The supposed boundary conditions for interior connections are a commonplace assumption which is utilized by many researchers [135-137].

Dimensions of simulated beams and column are deemed constant in all models, in which W36X150 and W14X398 sections are used for beams and column, respectively. The interior joint consists of a $3.65 \mathrm{~m}$ column and two beams with half-length of $3.65 \mathrm{~m}$ fully welded by fillet-welds to connect the beam and the column, as shown in Fig. 2. The modeled interior connection is extracted from a MRF system which is designed based on the Iranian steel building code and Iranian code "Standard 2800" for seismic resistant design of buildings using the structural analysis software, SAP 2000; in addition; in the afore-mentioned structure, the loading algorithm (the imposed dead load, live load, etc.) is as recommended by design codes (according to Fig. 2). Continuity plates are considered to enhance the column strength as well as transferring the forces from beam to column. Furthermore, doubler plates with thickness of $0.025 \mathrm{~m}$ are considered on both sides of panel zone.

In order to investigate the performance of frame, monotonic lateral loading is applied at the tip of the column with steps of $0.002 \mathrm{rad}$ drift ratio. On the other words, the displacement is imposed at the top of the column increasingly until the connection is failed. The loading system is illustrated in
Fig. 2. Based on the [29], the capability of the connection to tolerate the inter-story drift ratio of $0.04 \mathrm{rad}$ is required in the seismic-force resisting systems, where the loss of flexural resistance of the connection is not exceeding 0.2 of plastic moment capacity. Consequently, the failure criteria include the weld fracture, local buckling of the beam web, strength loss exceeding $20 \%$ of the capacity and plastic strain reaching the ultimate strain of base material.

A parametric study is performed to study the effect of openings on the behavior of interior connections. To do so, an isolated circular opening is considered in RWS models in beam web with 2 influential parameters including the distance of opening from column face and opening diameter. The distance of the opening center from the column face is considered to be $0.87 \mathrm{~h}, 1.3 \mathrm{~h}$, and $1.74 \mathrm{~h}$. Furthermore, 3 different diameters are considered for opening as well, including $0.5 \mathrm{~h}, 0.65 \mathrm{~h}$, and $0.8 \mathrm{~h}$ in which $\mathrm{h}$ is the beam depth. It should be noted that the parameters are taken from the research done by [94]. Similarly, the influential dimensions of DF connections such as $\mathrm{L}^{*} / \mathrm{D}$ and $\mathrm{L} / \mathrm{D}$ are considered in accordance with the studies performed by [34, 138], respectively. In the afore-mentioned studies, the parameter $L^{*} / \mathrm{D}$ was suggested to be in the range of 3 to 5 and the desired ratio for L/D parameter was taken equal to 2 , where $\mathrm{L}^{*}, \mathrm{~L}$, and $\mathrm{D}$ are indicants of the distance between the void and column face, length of opening, and opening diameter, respectively. Accordingly, the $L^{*} / \mathrm{D}$ parameter is considered to be 4 in all DF models and L/D is considered to be equal 2 in the HS-40-55-60 model.

Summary and configuration of the studied models are presented in Table 2 and Fig. 3, as well. Also, Fig. 4 indicates the finite element models of different configurations.

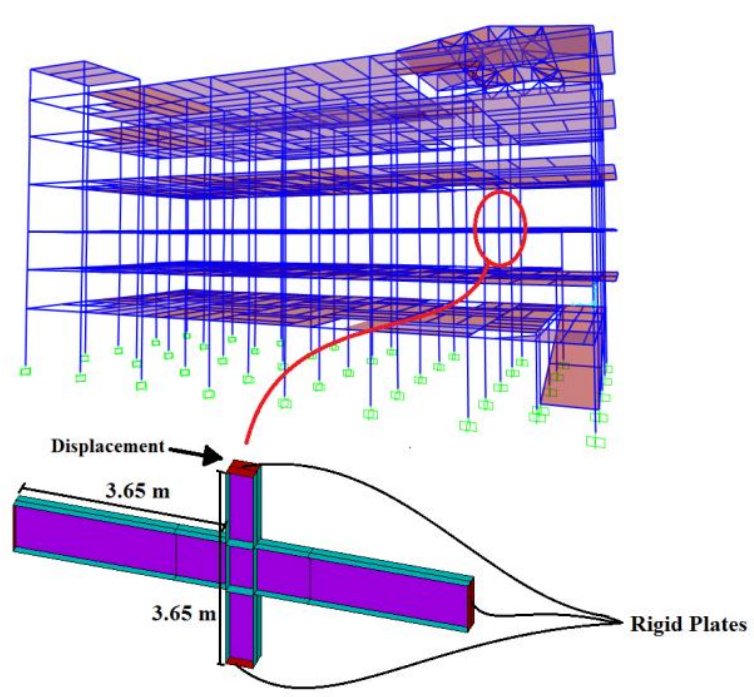

Fig. 2 Location and dimension of studied interior connection

\section{Results}

Fig. 5 to 7 present the lateral force-story drift curves of studied models. Also, the Von Mises plastic strain distribution of models in 0.04 story drift is illustrated in Fig. 8.

The brittle failure of the beam-to-column connection in ordinary fully welded rigid connection has occurred at $3.6 \%$ story drift. However, introduction of appropriate openings in beam web or flange prevents the premature failure of the connection and brings about the plastic hinge initiation in beam web or flange, away from the critical area. Furthermore, according to the results, utilizing the typical RBS connection prevents connection failure and leads to the increased ductility, which is a desirable behavior. The studied RBS connection, designed in accordance with AISC 358-16, fails at $4.2 \%$ story drift, as illustrated in Fig. 7, due to steel rupture.

Although RBS connection is capable of fulfilling the expected performance through leading the failure toward the beam which is considered a ductile behavior, it experiences excessive loss of lateral strength as well as initial stiffness. Compared to RBS connections, drilled flange connections are considered a more practical method in terms of beam flange cut. Based on the results, DF category in which openings are implemented in beam flange, models with different width of singular horizontal slot including DF-HS-40, DF-HS-55, and DF-HS-60 experience an early failure due to more than $20 \%$ loss of lateral force at early stages of loading. However, no plastic strain was observed in the vicinity of connection. On the other hand, model with 3 different width of horizontal slots, DF-HS-40-55-60, performs better than the 
models with similar width of singular horizontal slot, as the story drift of 0.04 $\mathrm{rad}$ is reached without connection failure. Based on the Von Mises plastic strain distribution illustrated in Fig. 8, the initiation of plastic hinge has occurred at the opening edge, and the model is perfectly capable of leading the plastic hinge away from the column face.

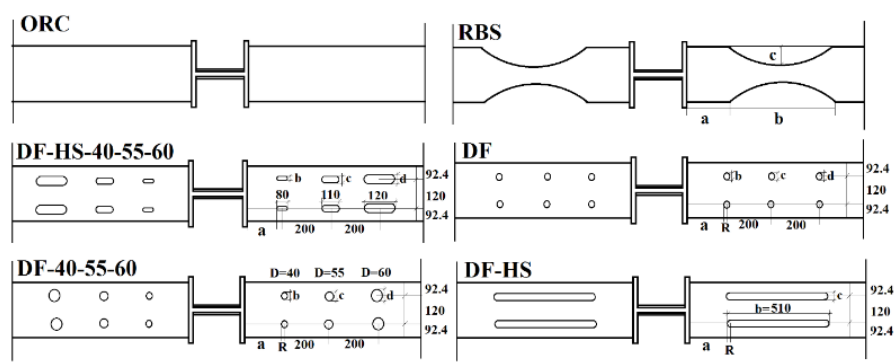

Top View

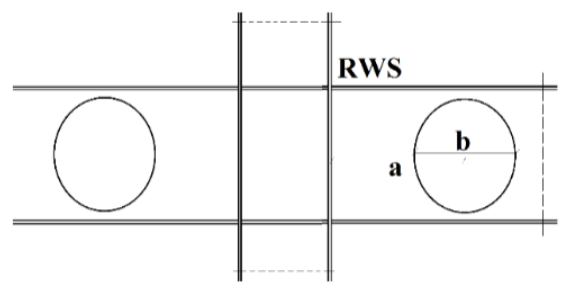

Side View

Fig. 3 Configuration of studied models
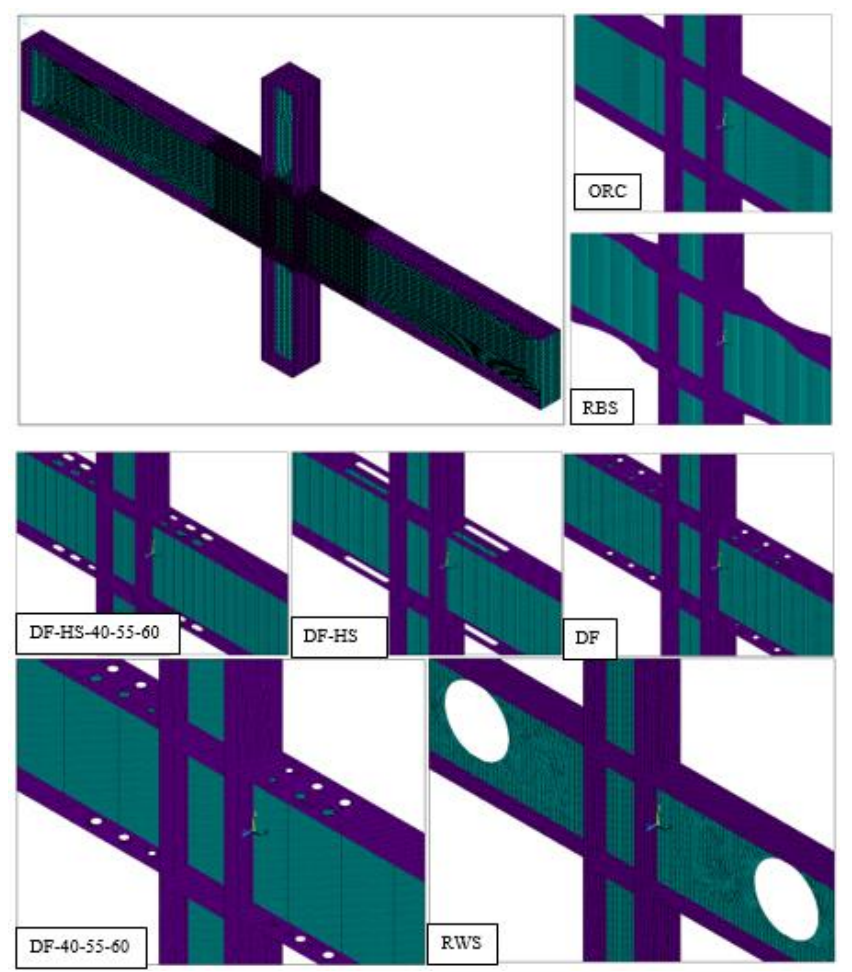

Fig. 4 FE models of different configurations

The initial stiffness of models with 3 circular openings, drilled in 2 rows at beam flange, is higher than the models with singular horizontal opening. The highest initial stiffness and lateral force belongs to the DF-40-40-40 model, in which the connection has experienced weld failure in 0.04 rad story drift. Furthermore, based on the Von Mises plastic strain distribution, the model has failed to move the developed strain away from the connection region. On the other hand, increasing the opening radii leads to the decreased Von-Mises Plastic strain at connection area. However, DF-55-55-55 and DF-60-60-60 models are incapable of reaching 0.04 rad story drift due to steel rupture in opening edges. Use of different opening diameters as indicated in
Fig. 5 and Fig. 8 results in a sought-after behavior of interior connection, in which the openings are capable of transmitting the plastic hinge towards the beam length without experiencing beam-to-column connection failure. The lateral force-story drift curve of this model is almost similar to the DF-55-55-55 model with the difference that the DF-40-55-60 model can sustain story drift of $0.044 \mathrm{rad}$ up to its failure. It must be noted that the maximum lateral force of DF-40-55-60 is 7\% less than the model DF-40-40-40 which has the highest maximum lateral force amongst the models with opening in beam flange. Yet, DF-40-55-60 has exhibited higher story drift, hence, higher ductility. Furthermore, in terms of initial stiffness, max lateral force, ductility, and the failure drift, interior connections with circular openings consisting of 3 various diameters perform better than the interior connections with 3 horizontal slots having different opening width. Overall, based on the results, model DF-40-55-60 reveals the desired performance amongst the other models, this finding supports previous research into this area by [34].

Also, according to the results, RWS category with singular large opening in beam web is capable of transferring the plastic hinge toward the beam mid-span, provided that the opening radii and the distance between the opening center and column face is selected appropriately. Comparing the developed plastic strain in the beam-to-column critical regions of ORC and RWS models, it is evident that the maximum developed plastic strain as well as highest lateral force has occurred in the model with no opening (ORC). Also, comparing the lateral force-story drift curves of models in terms of the mentioned influential parameters, there was a significant correlation between the ultimate lateral force and the opening radii, indicating that increasing the opening diameter results in the significant decrease of initial stiffness and frame lateral force, as shown in Fig. 6. However, shortening the distance between opening center and the column face causes degradation in lateral force as well as initial stiffness and intensifies the plastic strain in the critical area. Nevertheless, by decreasing the distance of the opening center from the column face, the amount of the lateral force declines slightly. Based on the results, diameters of $0.65 \mathrm{~h}$ and $0.8 \mathrm{~h}$ as well as parameter 'a' which is equal to $1.3 \mathrm{~h}$ and $1.74 \mathrm{~h}$ can reduce the plastic strain, developed in beam-to-column connection region. Based on the Von Mises plastic strain distribution, appropriate selection of opening size and distance leads to the occurrence of Vierendeel mechanism, hence, increased ductility. The results are in accordance with the [94].

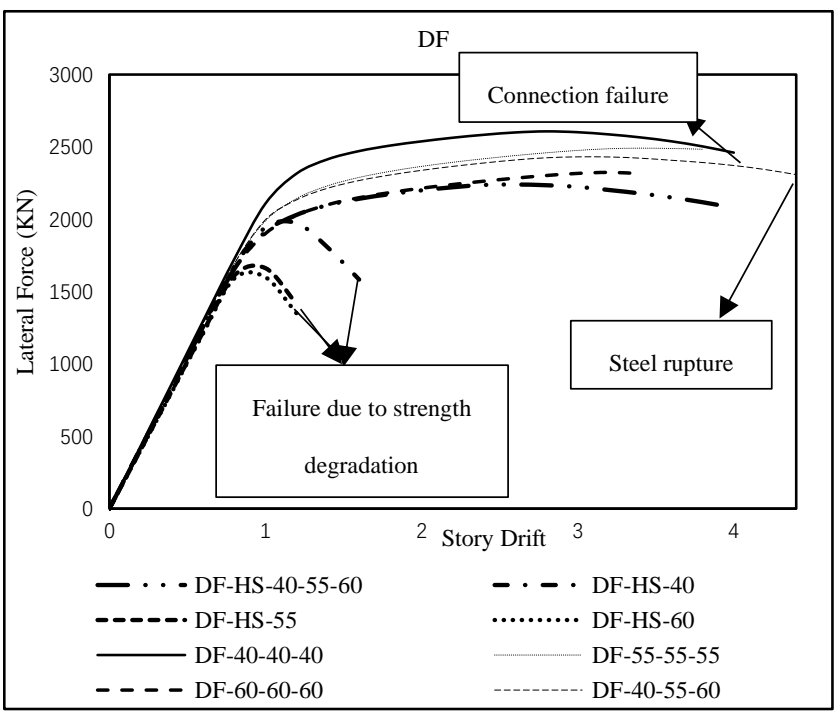

Fig. 5 lateral force-story drift curves of models with opening in beam flange (DF category) 


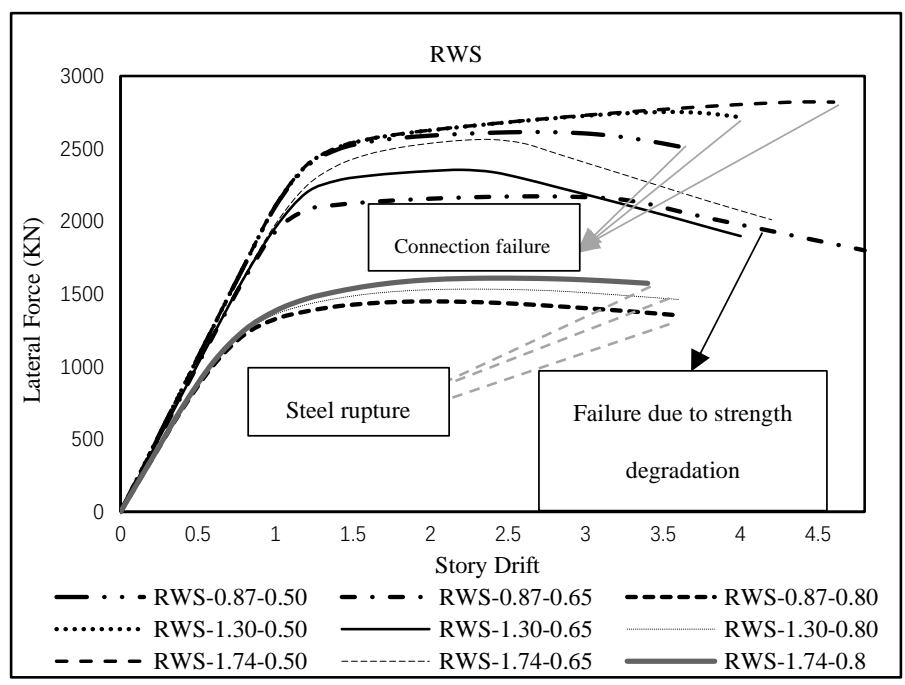

Fig. 6 Lateral forc-story drift curves of models with opening in beam web

\section{Discussion}

Fig. 7 indicates the lateral force-story drift curves of models in which the story drift of $0.04 \mathrm{rad}$ is reached. Also, the maximum lateral force of interior connections as well as lateral force of frames at 0.04 story drift is presented in Fig. 9 and Fig. 10, respectively. The DF and RWS curves are placed between ORC (reference) and RBS models. Based on the results, the behavior of RWS-1.7-0.5 and RWS-1.3-0.5 models are almost similar to the ORC model, with the difference that RWS-1.7-0.5 and RWS-1.3-0.5 models can withstand story drift up to $4.6 \%$ and $4 \%$, respectively. Besides, the degradation of initial stiffness due to introduction of the opening is insignificant in both models and can be neglected. As can be seen in Fig. 8, both models are incapable of transferring the plastic hinge toward the vicinity of the opening, hence, the failure has occurred due to connection fracture. Although initial stiffness of the DF-40-40-40 model is similar to the reference model with a slight difference, the lateral resistance of the model is $12 \%$ less than the reference model. This is while, the mentioned model could not satisfy the expected behavior and the failure occurred because of connection fracture. The results show that in case of using DF connections, DF-40-55-60 and DF-HS-40-55-60 models are in accordance with the aim of the connection design in which moving the plastic hinge away from the column face is considered a sough-after behavior. However, DF-40-55-60 performs better than the model with horizontal slots (DF-HS-40-55-60), as the area of the openings in flange is lower than the other model. Furthermore, stress concentration is observed at the edge of openings in flange. Overall, in terms of using DF connections, it is propounded to utilize 2 rows of drilled flange with 3 circular openings in which by shortening the distance of the circular opening from the column face, the diameter of the openings decreases. RWS models including RWS-1.74-0.65, RWS-1.3-0.65, and RWS-0.87-0.65, have experienced local buckling at 2.6, 2.6, and 3.4\% drift, consequently, the lateral force-story drift curves of models is projected to decline after occurrence of local buckling. Although shear deformation and Vierendeel mechanism is evident in the mentioned models, according to the Fig. 8, the models are capable of transferring the failure toward the beam, hence, exhibiting desired performance. Furthermore, according to Fig. 9, it is conspicuous that increasing the area of the opening results in decreased lateral load resistance as well as decreased initial stiffness.

As illustrated in Fig. 9, the maximum lateral force of interior connection in RWS-1.74-0.65 is higher than both DF-40-55-60 and DF-HS-40-55-60 models while the maximum area of opening belongs to the mentioned model. In this regard, the lateral force of RWS-1.74-0.65 model at 0.04 story drift is $12 \%$ and $0.3 \%$ lower than the lateral force of DF-40-55-60 and DF-HS-40-55-60 models at 0.04 story drift. This is because the RWS model has experienced early loss of lateral force which stems from the initiation of local buckling. Accordingly, wise selection of opening sizes in RBS, RWS, and DF connections are of great importance and use of them is dependent on the site condition and implementation considerations as well as design principles.

It must be noted that connections in special moment frames (SMRFs), intermediate moment frames (IMFs), and ordinary moment frames (OMFs) are expected to withstand total rotations of $0.04,0.03$, and 0.02 radian while maintaining $0.03,0.02$, and 0.01 radian plastic rotations, respectively (AISC). The results drawn from the current study is indicant of the fact that RBS,
DF-40-55-60, DF-HS-40-55-60, DF-40-40-40, RWS-1.30-0.50, RWS-1.30-0.65, RWS-1.74-0.50, RWS-1.74-0.65, and RWS-0.87-0.65 connections are capable of retaining their strength till story drift angle of 0.04 rad and higher, and are capable of being utilized in the SMRF connections, while ordinary fully welded rigid connections, DF-HS connections, and rest of the studied connections experience early failure due to lateral resistance degradation, steel rupture, or brittle failure at early stages, moreover, from the perspective of initial stiffness, the initial stiffness of DF-HS connections are less than the other studied DF connections, the maximum initial stiffness is for the DF-40-40-40 model, which has the least opening are in flange. Among RWS connections, the highest initial stiffness belongs to the model with minimum opening area.

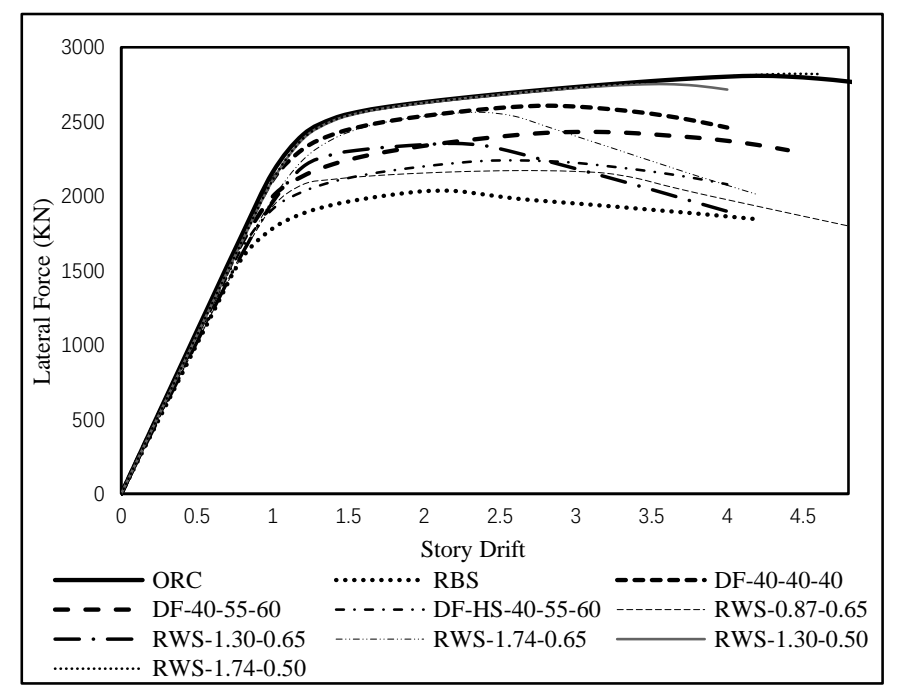

Fig. 7 Comparison of lateral force-story drift curves of DF, RWS, and RBS category with

the ORC (reference) model

From the ease of construction point of view, DF connections are considered more practical than RBS ones. the utilization of RWS connections are recommended where there is a need to provide pipelines, or ducts, etc., functionally. However, in case of wise selection of the opening sizes implemented in beam web or flange, DF and RWS connections can be sough-after substitutes for connections in SMRF systems.

Overall, the afore-mentioned connections correspond well with the expected rotational capacity of the SMRFs, OMFs, and IMFs. Nevertheless, few connections are available that have significantly larger rotation capacity as well as capability of leading the plastic hinge away from the column face and are suggested to be used in special moment frames among which DF-40-55-60 connections (DF connection with different opening diameters in flange), RWS connections with diameters of $0.65 \mathrm{~h}$ and $0.8 \mathrm{~h}$, and a parameter of $1.3 \mathrm{~h}$, and $1.74 \mathrm{~h}$ are suggested to be used in SMRF systems

\section{Conclusions}

There is a considerable amount of literature on intentionally attenuating a part of the beam whether in beam flange or web to relocate the plastic hinge away from the column face. Thus, this paper questions the behavior of interior connections with openings in beam web or flange subjected to monotonic loading through numerical simulation. The studied models are comprised of an ordinary fully welded rigid connection as a reference model, a model with prevalent RBS cut according to AISC 358-16, models with different configurations of flange cut (DF) as well as the models with singular opening in beam web (RWS). The obtained results are as follows:

The premature failure of the beam-to-column connection in ordinary fully welded rigid connections has led to intentional wakening of the beam as an approach to overcome the mentioned issue. Based on the numerical results, ordinary rigid connection experiences connection failure at $3.6 \%$ story drift while the prevalent RBS connection is capable of transferring the plastic hinge toward the beam length, hence, increasing the ductility, which is a sough-after performance. It should be noted that the failure drift of RBS connection due to steel rupture has occurred in $4.2 \%$ story drift. In other words, utilizing RBS connections in moment steel frames lead to an increase of $0.6 \%$ in story drift, in addition, the location of initiation of plastic hinge instead of column face (in ORC model) is led toward the beam length (reduced are) in RBS connections. 
Although RBS connection is capable of fulfilling the expected performance through leading the failure toward the beam which is a ductile behavior, it experiences excessive loss of lateral strength as well as initial stiffness which is calculated to be approximately $27 \%$ and $8 \%$, respectively, compared to the ORC model. Compared to RBS connections, drilled flange connections are easier to construct, hence, a more practical method in terms of beam flange cut. Based on the results, utilizing singular horizontal slot with different opening width in beam flange in 2 rows does not lead to the expected outcome and models experience an early failure due to loss of strength and the failure drift is less than $2 \%$ story drift due to excessive loss of lateral force which is considered to be $20 \%$. However, model with 3 horizontal slots, having different opening width, results in the desired performance in which the failure from beam-to-column connection region has been transferred towards the beam length, in other words, the model is fully capable of transferring the plastic hinge away from the column face, the failure drift is $4 \%$ story drift due to steel rupture around the opening edges.

The initial stiffness and maximum lateral force of circular openings in beam flange is higher than the models with elongated circular opening since the opening area is smaller, e.g. 5\% and 32\% degradation is observed in stiffness and maximum lateral force of model with elongated circular opening in which the opening diameter is $60 \mathrm{~mm}$ compared to the model with circular holes of $60 \mathrm{~mm}$ diameter. The same conclusion can be drawn for models with different diameters of openings, since increasing the diameter of drilled holes leads to the decease of both initial stiffness and lateral force in a way that the loss of stiffness and lateral force in the model with opening diameter of 60 $\mathrm{mm}$ compared to the model with opening diameter of $40 \mathrm{~mm}$ is estimated to be $3 \%$ and $6 \%$, approximately. Nevertheless, models with circular openings experience increased Von Mises plastic strain distribution in beam-to-column regions.

However, the use of openings with different diameters brings about an increase in frame ductility as well as transferring the plastic hinge away from the critical region, hence, sough-after substitute for identical opening diameters. In the afore-mentioned model, the failure drift is $4.4 \%$ which is the highest experienced drift among models with drilled flange. In addition, the stiffness and lateral force degradation, which is respectively $1.5 \%$ and $7 \%$, is negligible compared to the model with 3 drilled holes of $40 \mathrm{~mm}$, yet, the failure in model with 3 different opening diameters is due to steel rupture, while connection fracture is the cause of failure in model with 3 opening having the same diameters.

RWS connections, which consist of circular opening in beam web, fulfill the condition of moving the plastic hinge away from the column face in case of proper selection of opening size and location. Although increasing the opening radii leads to the reduced plastic strain in beam-to-column connection region, it significantly reduces the lateral force and stiffness of the frame. Furthermore, moving the opening away from the column face results in desired performance of the frame in terms of maximum lateral force and initial stiffness, accordingly, it is concluded that the model with opening diameter of 0.8 beam height in which the distance between the column face and opening center is considered to be 0.87 beam height has the lowest values in terms of initial stiffness and lateral force whereas the highest amounts of initial stiffness and lateral force belongs to the model with opening diameter 0.5 times the beam height in which the opening center distance from the column face is considered to be 1.74 times the opening height, the difference of the amount of initial stiffness and lateral force between the mentioned models is respectively considered to be $17 \%$ and approximately $50 \%$. Despite the fact that the model with minimum opening radii in conjunction with the maximum opening distance from the column face is expected to have the desired performance in terms of initial stiffness and lateral resistance, the model might be incapable of transferring the plastic hinge away from the column face due to insufficient weakening of beam web. It is concluded that shear deformation and local buckling is observed in RWS connections while in DF connections, stress concentration around the opening is critical.
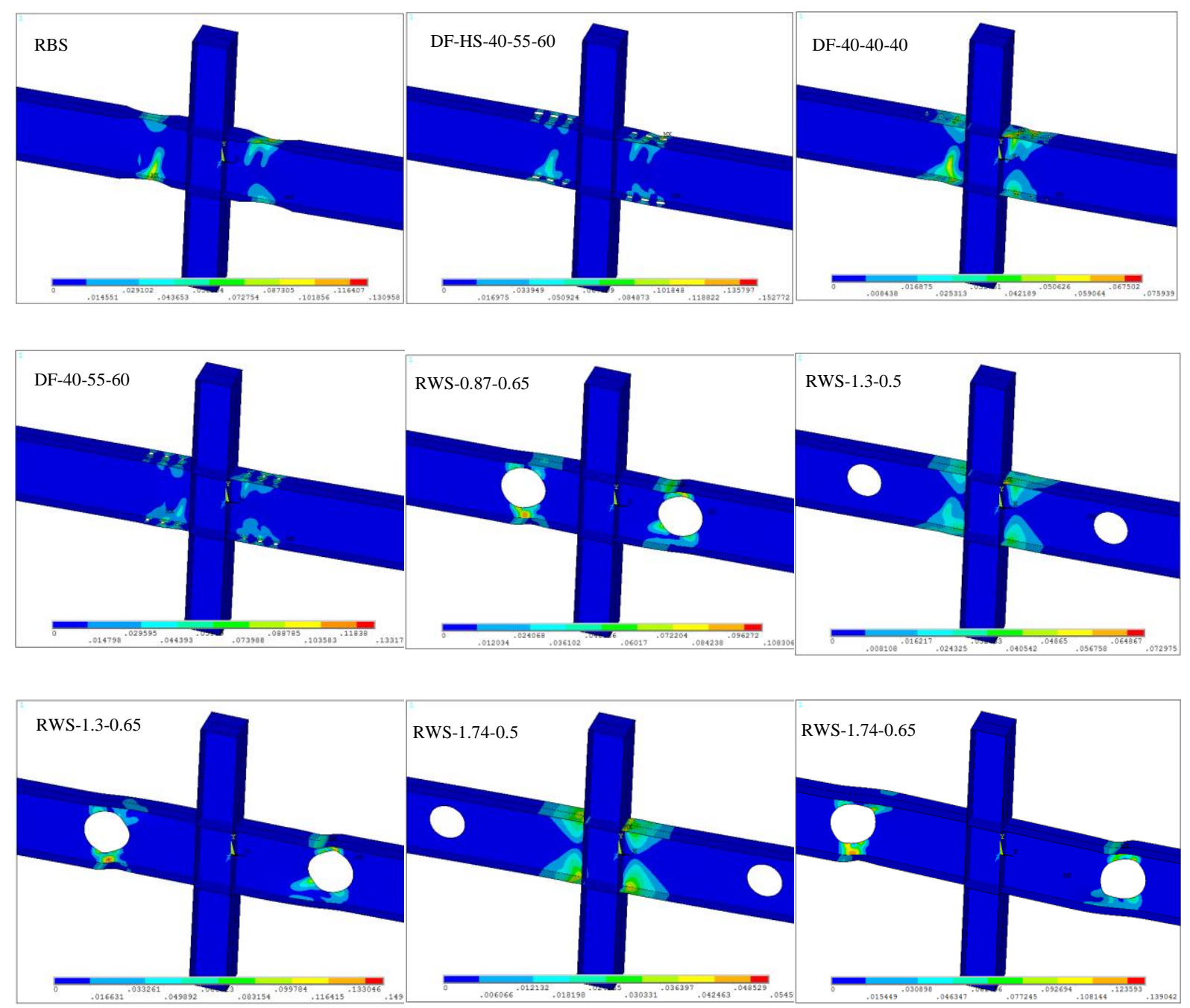
Table 2

specification of studied models

\begin{tabular}{|c|c|c|c|c|c|c|}
\hline Category & Model & $\mathrm{a}(\mathrm{mm})$ & $\mathrm{b}(\mathrm{mm})$ & $\mathrm{c}(\mathrm{mm})$ & $\mathrm{d}(\mathrm{mm})$ & Description \\
\hline ORC & ORC & - & - & - & - & Ordinary fully welded rigid connection \\
\hline \multirow[t]{4}{*}{ RBS } & RBS & 225 & 680 & 75 & - & Prevalent reduced beam flange according to AISC 358-16 \\
\hline & DF-HS-40-55-60 & 160 & 40 & 55 & 60 & 3 horizontal slots with $\mathrm{L} / \mathrm{D}=2$ and different opening diameter \\
\hline & DF-HS-40 & 160 & 510 & 40 & - & Single horizontal slot with $\mathrm{L}=510 \mathrm{~mm}$ and $\mathrm{D}=40 \mathrm{~mm}$ \\
\hline & DF-HS-55 & 220 & 510 & 55 & - & Single horizontal slot with $\mathrm{L}=510 \mathrm{~mm}$ and $\mathrm{D}=55 \mathrm{~mm}$ \\
\hline \multirow{9}{*}{ DF } & $\mathrm{DF}-\mathrm{HS}=60$ & 240 & 510 & 60 & - & Single horizontal slot with $\mathrm{L}=510 \mathrm{~mm}$ and $\mathrm{D}=60 \mathrm{~mm}$ \\
\hline & DF-40-40-40 & 160 & 40 & 40 & 40 & 3 circular voids with similar diameters of $40 \mathrm{~mm}$ \\
\hline & DF-55-55-55 & 220 & 55 & 55 & 55 & 3 circular voids with similar diameters of $55 \mathrm{~mm}$ \\
\hline & DF-60-60-60 & 240 & 60 & 60 & 60 & 3 circular voids with similar diameters of $60 \mathrm{~mm}$ \\
\hline & DF-40-55-60 & 160 & 40 & 55 & 60 & 3 circular voids with diameters of 40,55 , and $60 \mathrm{~mm}$ \\
\hline & RWS-0.87-0.50 & 793. & 455 & - & - & \\
\hline & RWS-0.87-0.65 & 793. & 592 & - & - & \\
\hline & RWS-0.87-0.80 & 793. & 729 & - & - & \\
\hline & RWS-1.30-0.50 & 1185 & 455 & - & - & \\
\hline \multirow[t]{5}{*}{ RWS } & RWS-1.30-0.65 & 1185 & 592 & - & - & Circular opening at beam web with various a and $b$ parameter \\
\hline & RWS-1.30-0.80 & 1185 & 729 & - & - & \\
\hline & RWS-1.74-0.50 & 1585 & 455 & - & - & \\
\hline & RWS-1.74-0.65 & 1585 & 592 & - & - & \\
\hline & RWS-1.74-0.80 & 1585 & 729 & - & - & \\
\hline
\end{tabular}

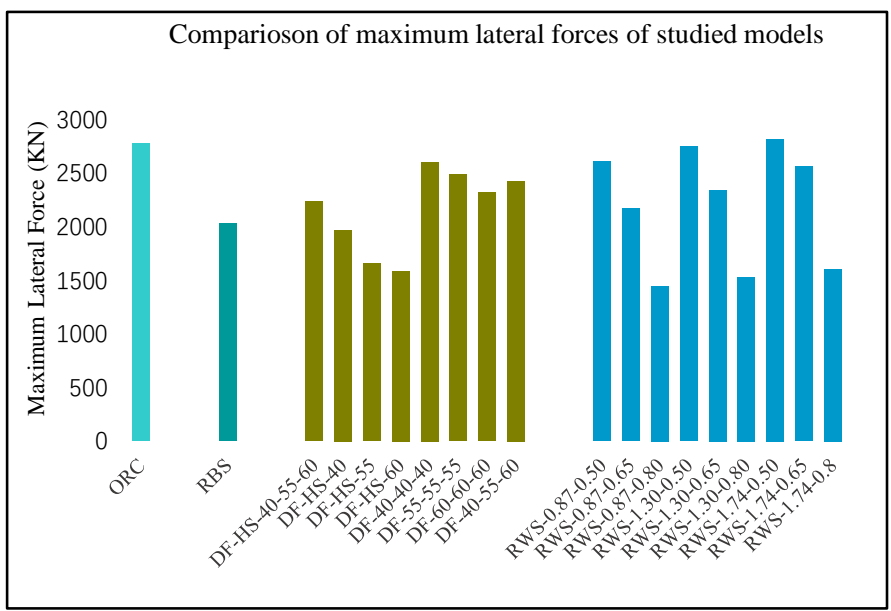

Fig. 9 Comparison of maximum lateral forces of studied models

\section{References}

[1] AISC 358 (2016), Prequalified Connections for Special and Intermediate Steel Moment Frames for Seismic Applications, American Institute of Steel Construction; Chicago, Illinois, USA.

[2] Ohsaki, M., H. Tagawa, and P. Pan. "Shape optimization of reduced beam section under cyclic loads." Journal of Constructional Steel Research 65, no. 7 (2009): 1511-1519.

[3] Pachoumis, D. T., E. G. Galoussis, C. N. Kalfas, and A. D. Christitsas. "Reduced beam section moment connections subjected to cyclic loading: Experimental analysis and FEM simulation." Engineering Structures 31, no. 1 (2009): 216-223.

[4] Pachoumis, D. T., E. G. Galoussis, C. N. Kalfas, and I. Z. Efthimiou. "Cyclic performance of steel moment-resisting connections with reduced beam sections - experimental analysis and finite element model simulation." Engineering Structures 32, no. 9 (2010): 2683-2692.

[5] Bartley, Tony C., and Janice J. Chambers. "State-of-the-art analysis of frames with reduced beam section connections." In Structures Congress 2008: Crossing Borders, pp. 1-10. 2008.

[6] Shen, Jie-Hua Jay, A. Astaneh-Asl, and D. B. McCallen. "Use of deep columns in special steel moment frames." Steel Tip Rep 24 (2002).

[7] Zhang, Xiaofeng, and James M. Ricles. "Experimental evaluation of reduced beam section connections to deep columns." Journal of Structural Engineering 132, no. 3 (2006a): 346-357.

[8] Zhang, Xiaofeng, and James M. Ricles. "Seismic behavior of reduced beam section moment connections to deep columns." Journal of structural engineering 132, no. 3 (2006b): 358-367.

[9] Chen, Sheng-Jin, and Y. C. Chao. "Effect of composite action on seismic performance of steel moment connections with reduced beam sections." Journal of Constructional Steel Research 57, no. 4 (2001): 417-434.

[10] FEMA-355D. State of the art report on connection performance. Washington (DC): Federal Emergency Management Agency; 2000.

[11] Carter, Charles J., and Nestor R. Iwankiw. "Improved ductility in seismic steel moment

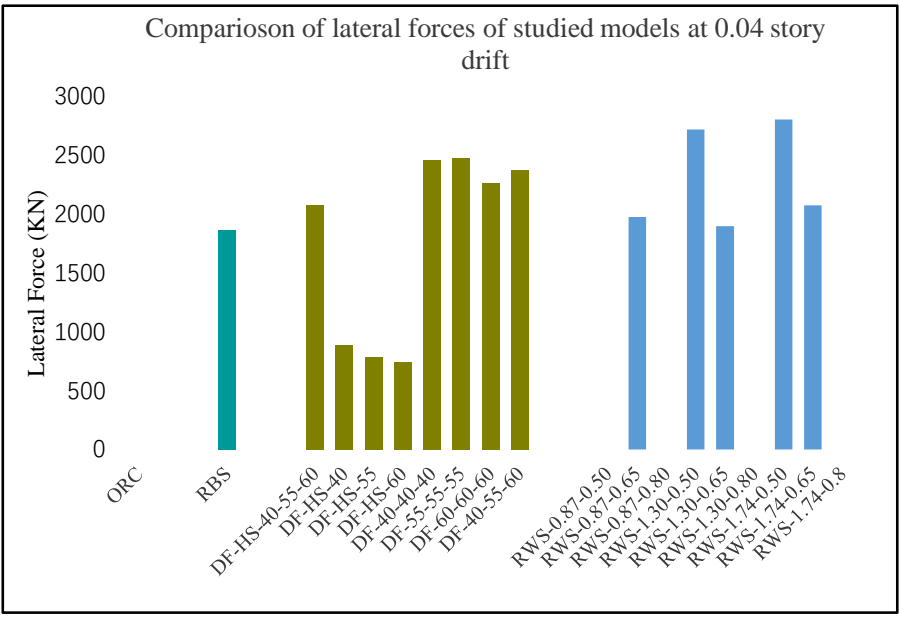

Fig. 10 Comparison of lateral forces of studied models at 0.04 rad story drift

frames with dogbone connections." Journal of Constructional Steel Research 1, no. 46 (1998): 448.

[12] Chen, Sheng-Jin, C. H. Yeh, and J. M. Chu. "Ductile steel beam-to-column connections for seismic resistance." Journal of Structural Engineering 122, no. 11 (1996): 1292-1299.

[13] IwankiW, NeStor. "Ultimate strength considerations for seismic design of the reduced beam section (internal plastic hinge)." Engineering Jouranal 1 (1997): quarter.

[14] Chi, Brandon, Chia-Ming Uang, and Albert Chen. "Seismic rehabilitation of pre-Northridge steel moment connections: A case study." Journal of Constructional Steel Research 62, no. 8 (2006): 783-792.

[15] Deylami, A., and A. Moslehi Tabar. "Promotion of cyclic behavior of reduced beam section connections restraining beam web to local buckling." Thin-Walled Structures 73 (2013): $112-120$.

[16] Tahamouli Roudsari, M., H. Jamshidi K, and M. Mohebi Zangeneh. "Experimental and numerical investigation of IPE reduced beam sections with diagonal web stiffeners." Journal of Earthquake Engineering 22, no. 4 (2018): 533-552.

[17] TahamouliRoudsari, M., and M. Torkaman. "Experimental and numerical investigations of rigid IPE beam connections with drilled flange and web stiffener." In Structures, vol. 16, pp 303-316. Elsevier, 2018.

[18] ASCE 23-97. Specifications for Structural Steel Beams with Web Openings. American Society of Civil Engineers 1999 / 30 pp.

[19] Lucas, Warren K., and David Darwin. Steel and composite beams with web openings. University of Kansas Center for Research, Inc., 1990.

[20] Lawson, R. M., and S. J. Hicks. Design of composite beams with large web openings: in accordance with Eurocodes and the UK National Annexes. Steel Construction Institute, 2011.

[21] Hedayat, Amir A., and Murude Celikag. "Post-Northridge connection with modified beam end configuration to enhance strength and ductility." Journal of Constructional Stee Research 65, no. 7 (2009): 1413-1430. 
[22] Chung, K. F., T. C. H. Liu, and A. C. H. Ko. "Investigation on Vierendeel mechanism in steel beams with circular web openings." Journal of Constructional Steel Research 57, no. 5 (2001): 467-490.

[23] Liu, T. C. H., and K. F. Chung. "Steel beams with large web openings of various shapes and sizes: finite element investigation." Journal of constructional steel research 59, no. 9 (2003): 1159-1176.

[24] Tsavdaridis, Konstantinos Daniel, and Cedric D’Mello. "Vierendeel bending study of perforated steel beams with various novel web opening shapes through nonlinear finite-element analyses." Journal of Structural Engineering 138, no. 10 (2012a): 1214-1230.

[25] Tsavdaridis, Konstantinos Daniel, and Cedric D'Mello. "Optimisation of novel elliptically-based web opening shapes of perforated steel beams." Journal of Constructional Steel Research 76 (2012b): 39-53.

[26] De'nan, Fatimah, Hazwani Hasan, Duaa Khaled Nassir, Mohd Hanim Osman, and Sariffuddin Saad. "Finite element analysis for torsion behavior of flat web profile beam steel section with opening." Procedia Engineering 125 (2015): 1129-1134.

[27] FEMA-350. Recommended seismic design criteria for new steel moment-frame buildings. Washington (DC): Federal Emergency Management Agency; 2000

[28] FEMA P-750. Council, B. S. S. (2009). NEHRP recommended seismic provisions for new buildings and other structures, 2009 edition. Federal Emergency Management Agency, Washington, DC.

[29] AISC 341 (2016), Seismic Provisions for Structural Steel Buildings, American Institute of Steel Construction; Chicago, Illinois, USA.

[30] Maleki, Mehdi, Roohollah Ahmady Jazany, and Mohammad Soheil Ghobadi. "Seismic fragility assessment of SMRFs with drilled flange connections using ground motion variability." KSCE Journal of Civil Engineering 23, no. 4 (2019): 1733-1746.

[31] Farrokhi, Hooman, F. Danesh, and Sassan Eshghi. "A modified moment resisting connection for ductile steel frames (Numerical and experimental investigation)." Journal of Constructional Steel Research 65, no. 10-11 (2009): 2040-2049.

[32] Vetr, M., M. Miri, and A. Haddad. "Seismic behavior of a new reduced beam section connection by drilled holes arrangement (RBS_DHA) on the beam flanges through experimental studies." In 15th world conference of earthquake engineering (15WCEE), Lisbon, Portugal. 2012

[33] Vetr, M., and A. Haddad. "Study of drilled flange connection in moment resisting frames." In Report No. 3732. International Institute of Earthquake Engineering and Seismology Tehran; Iran, 2010.

[34] Atashzaban, Ardavan, Iman Hajirasouliha, Roohollah Ahmady Jazany, and Mohsen Izadinia. "Optimum drilled flange moment resisting connections for seismic regions." Journal of Constructional Steel Research 112 (2015): 325-338.

[35] Bojórquez, E., López-Barraza, A., Reyes-Salazar, A., Ruiz, S. E., Ruiz-García, J., Formisano, A., ... \& Bojórquez, J. Improving the structural reliability of steel frames using posttensioned connections. Advances in Civil Engineering, 2019.

[36] Qu, W., Zhao, E., \& Zhou, Q. Refined analysis of fatigue crack initiation life of beam-to-column welded connections of steel frame under strong earthquake. Shock and Vibration, (2017).

[37] Faridmehr, I., Tahir, M. M., Lahmer, T., \& Osman, M. H. Seismic performance of steel frames with semirigid connections. Journal of Engineering, (2017).

[38] Yan, Shen, Kim JR Rasmussen, Lu-li Jiang, Chen Zhu, and Hao Zhang. "Experimental evaluation of the full-range behaviour of steel beam-to-column connections." Advanced Steel Construction 16, no. 1 (2020): 77-84.

[39] da Silva, Luís Simões, Sara Oliveira, Ricardo Costa, and Filippo Gentili. "DESIGN AND ANALYSIS OF STEEL STRUCTURES CONSIDERING THE 3D BEHAVIOUR OF THE JOINTS." ADVANCED STEEL CONSTRUCTION 16, no. 2 (2020): 137-145.

[40] Zhang, Yan-xia, Quan-gang Li, Wei-zhen Huang, Kun Jiang, and Yu Sun. "Behavior of prefabricated beam-column connection with short strands in self-centering steel frame." Advanced Steel Construction 15, no. 2 (2019): 203-214.

[41] Ding, Chenting, Xuebei Pan, Yu Bai, and Gang Shi. "Prefabricated connection for steel beam and concrete-filled steel tube column." Journal of Constructional Steel Research 162 (2019): 105751.

[42] Zhang, Ai-Lin, Guang-Hao Shangguan, Yan-Xia Zhang, Qing-Bo Wang, and Wen-Chao Cai. "Experimental study of resilient prefabricated steel frame with all-bolted beam-to-column connections." ADVANCED STEEL CONSTRUCTION 16, no. 3 (2020): 255-271.

[43] Gholami, M., M. Tehranizadeh, and A. Deylami. "Evaluation of welded flange plate connections between steel beams and box columns." Advanced Steel Construction 9, no. 1 (2013): 59-76.

[44] Xue, Su-duo, Si-yao Li, Xiong-yan Li, and Chen Yao. "BEHAVIOUR AND MATHEMATICAL MODEL FOR SEMI-RIGID THREADED-SLEEVE CONNECTION." ADVANCED STEEL CONSTRUCTION 15, no. 2 (2019): 123-128.

[45] Liu, Hong-bo, Ying-jie Zhang, Lan Wang, and Zhi-hua Chen. "Mechanical performance of welded hollow spherical joints at elevated temperatures." Advanced Steel Construction 16, no. 1 (2020): 1-12.

[46] Ma, Rong-Quan, Ping-Yu Zhao, Hui-Yong Ban, Yuan-Qing Wang, Yu-Zheng Zhao, and Cheng-Bo Peng. "BEHAVIOUR OF REINFORCED JOINTS BETWEEN STEEL BEAM AND L-SHAPED WIDE LIMB COMPOSITE COLUMN." BEHAVIOUR 17, no. 1 (2021): 66-72.

[47] Meng, Bao, Liang-De Li, Wei-Hui Zhong, Ji-Ping Hao, and Zheng Tan. "ENHANCING COLLAPSE-RESISTANCE OF STEEL FRAME JOINTS BASED ON FOLDED AXILLARY PLATES." ADVANCED STEEL CONSTRUCTION 17, no. 1 (2021): 84-94.

[48] Engelhardt, Michael D., Ted Winneberger, Andrew J. Zekany, and Timothy J. Potyraj. "Experimental investigation of dogbone moment connections." (1998).

[49] Plumier, Andre. "The dogbone: back to the future." Engineering Journal-American Institute of Steel Construction 34 (1997): 61-67.

[50] Engelhardt, Michael D., G. Fry, S. Jones, M. Venti, and S. Holliday. "Behavior and design of radius cut reduced beam section connections." Rep. No. SAC/BD-00 17 (2000).

[51] Jones, Scott L., Gary T. Fry, and Michael D. Engelhardt. "Experimental evaluation of cyclically loaded reduced beam section moment connections." Journal of Structural Engineering 128, no. 4 (2002): 441-451.

[52] Zhang, Xiaofeng, James M. Ricles, Le-Wu Lu, and John W. Fisher. "Development of seismic guidelines for deep-column steel moment connections." (2004).

[53] Chen, Cheng-Chih, Chun-Chou Lin, and Chieh-Hsiang Lin. "Ductile moment connections used in steel column-tree moment-resisting frames." Journal of Constructional Steel Research 62, no. 8 (2006): 793-801.

[54] Oh, Sang-Hoon, Young-Ju Kim, and Tae-Sup Moon. "Cyclic performance of existing moment connections in steel retrofitted with a reduced beam section and bottom flange reinforcements." Canadian journal of civil engineering 34, no. 2 (2007): 199-209.
[55] Zhang, Xiaofeng, and James M. Ricles. "Seismic behavior of reduced beam section momen connections to deep columns." Journal of structural engineering 132, no. 3 (2006): 358-367.

[56] Soliman, Amr A., Omar A. Ibrahim, and Abdelaziz M. Ibrahim. "Effect of panel zone strength ratio on reduced beam section steel moment frame connections." Alexandria engineering journal 57, no. 4 (2018): 3523-3533.

[57] Morshedi, Mohamad A., Kiarash M. Dolatshahi, and Shervin Maleki. "Double reduced beam section connection." Journal of Constructional Steel Research 138 (2017): 283-297.

[58] Plumier, Andre. "New idea for safe structures in seismic zones." In IABSE Symposium-Mixed Structures Including New Materials. 1990.

[59] Iwankiw, N. R., and J. Mohammadi. "Elastic in-plane stiffness for a circular cut reduced beam section (RBS)." ENGINEERING JOURNAL-AMERICAN INSTITUTE OF STEEL CONSTRUCTION INC 41, no. 1 (2004): 23-36.

[60] Jin, Jun, and Sherif El-Tawil. "Seismic performance of steel frames with reduced beam section connections." Journal of Constructional Steel Research 61, no. 4 (2005): 453-471.

[61] Chen, Sheng-Jin, and Chin-Te Tu. "Experimental study of jumbo size reduced beam section connections using high-strength steel." Journal of Structural Engineering 130, no. 4 (2004) $582-587$

[62] Tremblay, Robert, and André Filiatrault. "Seismic performance of steel moment resisting frames retrofitted with a locally reduced beam section connection." Canadian Journal of Civil Engineering 24, no. 1 (1997): 78-89

[63] Engelhardt, Michael D., and Thomas A. Sabol. "Reinforcing of steel moment connections with cover plates: benefits and limitations." Engineering structures 20, no. 4-6 (1998): $510-520$

[64] Yu, Qi-Song Kent, and Chia-Ming Uang. "Effects of near-fault loading and lateral bracing on the behavior of RBS moment connections." Steel and Composite Structures 1, no. 1 (2001): $145-158$

[65] Uang, Chia-Ming, Qi-Song "Kent Yu, Shane Noel, and John Gross. "Cyclic testing of steel moment connections rehabilitated with RBS or welded haunch." Journal of Structural Engineering 126, no. 1 (2000): 57-68.

[66] Lee, Cheol-Ho. "Seismic design of rib-reinforced steel moment connections based on equivalent strut model." Journal of Structural Engineering 128, no. 9 (2002): 1121-1129.

[67] Ghaderi, Mohsen, Mohsen Gerami, and Reza Vahdani. "A comparison of seismic low cycle fatigue and extremely low cycle fatigue on steel moment frames with reduced beam section connection (RBS)." International Journal of Fatigue 119 (2019): 139-149.

[68] Hong, Jong-Kook. "Sloped RBS moment connections at roof floor subjected to cyclic loading: Analytical investigation." International Journal of Steel Structures 19, no. 1 (2019): 329-339

[69] Fanaie, Nader, Shervin Safaei Faegh, and Fatemeh Partovi. "An improved and innovative formulation for calculating amplified elastic story drift induced by RBS connections in steel moment frames." Journal of Constructional Steel Research 160 (2019): 510-527.

[70] Lee, Cheol-Ho, Jong-Hyun Jung, and Sung-Yong Kim. "Cyclic seismic performance of weak-axis RBS welded steel moment connections." International Journal of Steel Structures 19, no. 5 (2019): 1592-1604

[71] Sofias, C. E., and D. T. Pachoumis. "Assessment of reduced beam section (RBS) moment connections subjected to cyclic loading." Journal of Constructional Steel Research 171 (2020): 106151.

[72] Di Benedetto, Sabatino, Antonella Bianca Francavilla, Massimo Latour, Giovanni Ferrante Cavallaro, Vincenzo Piluso, and Gianvittorio Rizzano. "Pseudo-dynamic testing of a full-scale two-storey steel building with RBS connections." Engineering Structures 212 (2020): 110494.

[74] Hamed, Arash Akbari, and Mohammad Charkhtab Basim. "Experimental-numerical study on weakened HSS-to-HSS connections using HBS and RBS approaches." In Structures, vol. 28 pp. 1449-1465. Elsevier, 2020.

[74] Parvari, Ali, S. Mehdi Zahrai, S. Mohammad Mirhosseini, and Ehsanollah Zeighami. "Comparing cyclic behaviour of RBS, DFC and proposed rigid connections in a steel moment frame with CFT column." Australian Journal of Civil Engineering (2020): 1-20.

[75] Lee, Sang-Yun, Sam-Young Noh, and Young-Soo Na. "Comparison of Progressive Collapse Resistance of Steel Moment Frame Systems with WUF-B verse RBS Connection Details." Journal of the Architectural Institute of Korea 36, no. 9 (2020): 145-156.

[76] Vajdian, Mehdi, S. Mehdi Zahraei, S. Mohammad Mirhosseini, and Ehsanollah Zeighami. "Investigation of Seismic Performance of (RBS) and Drilled Flange Connection (DFC) Containing rhombus Shaped Hole in Steel Moment Frames." Australian Journal of Civil Engineering 18, no. 2 (2020): 246-262.

[77] Meng, Bao, Weihui Zhong, Jiping Hao, and Xiaoyan Song. "Improving anti-collapse performance of steel frame with RBS connection." Journal of Constructional Steel Research 170 (2020): 106119

[78] Shariati, Mahdi, Mostafa Ghorbani, Morteza Naghipour, Nasrollah Alinejad, and Ali Toghroli. "The effect of RBS connection on energy absorption in tall buildings with braced tube frame system." Steel and Composite Structures 34, no. 3 (2020): 393-407.

[79] Nia, Majid Mohammadi, and Saber Moradi. "Effects of design factors on the cyclic response of sloped RBS moment connections." Engineering Structures 207 (2020): 110228

[80] Tippe, S. P., \& Kulkarni, P. M. "Finite element analysis of perforated beam-column connections." International Research Journal of Engineering and Technology, (2018): 5(1), 477-481.

[81] Tsavdaridis, Konstantinos Daniel, Christopher Pilbin, and Chun Kit Lau. "FE parametric study of RWS/WUF-B moment connections with elliptically-based beam web opening under monotonic and cyclic loading." International Journal of Steel Structures 17, no. 2 (2017): 677-694.

[82] Shin, Myoungsu, Seung-Pil Kim, Arne Halterman, and Mark Aschheim. "Seismic toughnes and failure mechanisms of reduced web-section beams: Phase 1 tests." Engineering Structures 141 (2017a): 198-216

[83] Shin, Myoungsu, Seung-Pil Kim, Arne Halterman, and Mark Aschheim. "Seismic toughnes and failure mechanisms of reduced web-section beams: Phase 2 tests." Engineering Structures 141 (2017b): 607-623

[94] Najafi, M., and Y. C. Wang. "Behaviour and design of steel members with web openings under combined bending, shear and compression." Journal of Constructional Steel Research 128 (2017): 579-600.

[85] Momenzadeh, Seyedbabak, Mohammad Taghi Kazemi, and Masoud Hoseinzadeh Asl. "Seismic performance of reduced web section moment connections." International Journal of Steel Structures 17, no. 2 (2017): 413-425.

[86] Morkhade, Samadhan G., and Laxmikant M. Gupta. "Experimental investigation for failure analysis of steel beams with web openings." Steel and Composite Structures 23, no. 6 (2017): 647-656.

[87] Kumar, SR Satish, and DV Prasada Rao. "RHS beam-to-column connection with web 
opening — experimental study and finite element modelling." Journal of Constructional Steel Research 62, no. 8 (2006): 739-746.

[88] Yang, Qingshan, Bo Li, and Na Yang. "Aseismic behaviors of steel moment resisting frames with opening in beam web." Journal of Constructional Steel Research 65, no. 6 (2009): 1323-1336.

[89] Ju, Young K., Do-Hyun Kim, and Sang-Dae Kim. "Experimental assessment of the shear strength of an asymmetric steel composite beam with web openings." Canadian Journal of Civil Engineering 32, no. 2 (2005): 314-328.

[90] Naimi, Sepanta, Murude Celikag, and Amir A. Hedayat. "Ductility enhancement of post-Northridge connections by multilongitudinal voids in the beam web." The Scientific World Journal 2013 (2013).

[91] Morkhade, Samadhan G., and Laxmikant M. Gupta. "Analysis of steel I-beams with rectangular web openings: experimental and finite element investigation." Engineering Structures and Technologies 7, no. 1 (2015): 13-23.

[92] Morkhade, Samadhan G., and L. M. Gupta. "Ultimate load behaviour of steel beams with web openings." Australian Journal of Structural Engineering 20, no. 2 (2019): 124-133.

[93] Tsavdaridis, Konstantinos Daniel, and Cedric D'Mello. "Web buckling study of the behaviour and strength of perforated steel beams with different novel web opening shapes." Journal of Constructional Steel Research 67, no. 10 (2011): 1605-1620

[94] Tsavdaridis, Konstantinos Daniel, Faezeh Faghih, and Nikolaos Nikitas. "Assessment of perforated steel beam-to-column connections subjected to cyclic loading." Journal of Earthquake Engineering 18, no. 8 (2014): 1302-1325.

[95] Tsavdaridis, Konstantinos Daniel, and Theodore Papadopoulos. "A FE parametric study of RWS beam-to-column bolted connections with cellular beams." Journal of Constructional Steel Research 116 (2016): 92-113.

[96] Shanmugam, N. E., V. T. Lian, and V. Thevendran. "Finite element modelling of plate girders with web openings." Thin-Walled Structures 40, no. 5 (2002): 443-464.

[97] Kazemi, M. T., and S. Erfani. "Analytical study of special girder moment frames using a mixed shear-flexural link element." Canadian Journal of Civil Engineering 34, no. 9 (2007): 1119-1130.

[98] Kıymaz, Güven, Erdal Coskun, and Edip Seçkin. "Transverse load carrying capacity of sinusoidally corrugated steel webs with web openings." (2010)

[99] Bayramoglu, Guliz. "Reliability analysis of tested steel I-beams with web openings." Structural Engineering and Mechanics 41, no. 5 (2012): 575-589.

[100] Erfani, Saeed, and Vahid Akrami. "Increasing seismic energy dissipation of steel moment frames using reduced web section (RWS) connection." Journal of Earthquake Engineering 21, no. 7 (2017): 1090-1112.

[101] Erfani, Saeed, Ata Babazadeh Naseri, and Vahid Akrami. "The beneficial effects of beam web opening in seismic behavior of steel moment frames." Steel and Composite Structures 13, no. 1 (2012): 35-46.

[102] Boushehri, Kavoos, Konstantinos Daniel Tsavdaridis, and Gaochuang Cai. "Seismic behaviour of RWS moment connections to deep columns with European sections." Journal of Constructional Steel Research 161 (2019): 416-435

[103] Goel, Subhash C., and Ahmad M. Itani. "Seismic behavior of open-web truss-moment frames." Journal of Structural Engineering 120, no. 6 (1994): 1763-1780.

[104] Elilarasi, K., S. Kasthuri, and B. Janarthanan. "EFFECT OF CIRCULAR OPENINGS ON WEB CRIPPLING OF UNLIPPED CHANNEL SECTIONS UNDER END-TWO-FLANGE LOAD CASE." ADVANCED STEEL CONSTRUCTION 16, no. 4 (2020): 310-320

[105] Goel, Subhash C., and Ahmad M. Itani. "Seismic-resistant special truss-moment frames." Journal of Structural Engineering 120, no. 6 (1994): 1781-1797.

[106] Naughton, Daniel Tomas, Konstantinos Daniel Tsavdaridis, Chrysanthos Maraveas, and Andreas Nicolaou. "Pushover analysis of steel seismic resistant Frames with reduced Web section and reduced Beam section connections." Frontiers in Built Environment 3 (2017): 59 .

[107] Nazaralizadeh, Hamidreza, Hamid Ronagh, Parham Memarzadeh, and Farhad Behnamfar. "Cyclic performance of bolted end-plate RWS connection with vertical-slits." Journal of Constructional Steel Research 173 (2020): 106236.

[108] Davarpanah, Mohammad, Hamid Ronagh, Parham Memarzadeh, and Farhad Behnamfar. "Cyclic behaviour of elliptical-shaped reduced web section connection." In Structures, vol. 24, pp. 955-973. Elsevier, 2020

[109] Davarpanah, Mohammad, Hamid Ronagh, Parham Memarzadeh, and Farhad Behnamfar. "Cyclic behavior of welded elliptical-shaped RWS moment frame." Journal of Constructional Steel Research 175 (2020): 106319.

[110] Yu, Haoran, and Weibin Li. "Comparison of steel frames with RWS and WFP beam-to-column connections through seismic fragility analysis." Advances in Structural Engineering (2020): 1369433220977284

[111] Lin, Shentong, Huiyun Qiao, Jinpeng Wang, Jiahao Shi, and Yu Chen. "Anti-collapse performance of steel frames with RWS connections under a column removal scenario." Engineering Structures 227 (2021): 111495

[112] Erfani, Saeed, Vahid Akrami, and Arash Mohammad-nejad. "Lateral load resisting behavior of steel moment frames with reduced web section (RWS) beams." In Structures, vol. 28, pp. 251-265. Elsevier, 2020.
[113] Bi, Ran, Lianguang Jia, Pengyu Li, and Qinghe Wang. "Multiparameter seismic behavior of castellated beam-to-column connections based on stress migration." In Structures, vol. 29, pp. 1137-1153. Elsevier, 2021.

[114] Asl, Masoud Hoseinzadeh, and Maryam Jahanian. "Behaviour of Steel Deep Beams in Moment Frames with Web Opening Subjected to Lateral Loading." International Journal of Steel Structures 20, no. 5 (2020): 1482-1497.

[115] Fanaie, Nader, and Hossein Sadeghi Moghadam. "Experimental study of rigid connection of drilled beam to CFT column with external stiffeners." Journal of Constructional Steel Research 153 (2019): 209-221.

[116] ALIBAKHSHI, MOHSEN, JAZANY ROOHOLLAH AHMADY, MOHAMMAD SOHEIL GHOBADI, and ABADI MASOMEH SAADAT MAKI. "CONSIDERING THE EFFECT OF HOLES DISTANCES OF BEAM FLANGES ON SEISMIC BEHAVIOR OF DRILLED FLANGE (DF) CONNECTIONS." (2015): 52-66.

[117] Atashzaban, A., M. Izadinia, JAZANY R. AHMADY, and I. HAJIRASOULIHA. "Seismic Performance of Drilled Flange Beam to Column Connections for Ductile Steel Frames." (2016): 53-65

[118] Jazany, Roohollah Ahmady. "Improved design of drilled flange (DF) moment resisting connection for seismic regions." Bulletin of Earthquake Engineering 16, no. 5 (2018): 1987-2020.

[119] Maleki, M., R. Ahmady Jazany, and M. S. Ghobadi. "Probabilistic seismic assessment of SMFs with drilled flange connections subjected to near-field ground motions." International Journal of Steel Structures 19, no. 1 (2019): 224-240.

[120] Fanaie, Nader, and Hossein Sadeghi Moghadam. "Experimental study of rigid connection of drilled beam to CFT column with external stiffeners." Journal of Constructional Steel Research 153 (2019): 209-221.

[121] Vajdian, Mehdi, S. Mehdi Zahraei, S. Mohammad Mirhosseini, and Ehsanollah Zeighami. "Investigation of Seismic Performance of (RBS) and Drilled Flange Connection (DFC) Containing rhombus Shaped Hole in Steel Moment Frames." Australian Journal of Civil Engineering 18, no. 2 (2020): 246-262.

[122] Vajdian, Mehdi, Ali Parvari, and Mohammad Afzali. "Improvement of Seismic Performance of Beam-column Connection With Replaceable Drilled Attachment Parts." Periodica Polytechnica Civil Engineering 64, no. 4 (2020): 1202-1218.

[123] Vajdian, Mehdi, S. Mehdi Zahrai, S. Mohammad Mirhosseini, and Ehsanollah Zeighami. "Cyclic Behavior of Variously Drilled Flange Beam Connected to Box Column." AUT Journal of Civil Engineering (2020).

[124] Parvari, Ali, Seyed Mehdi Zahrai, S. Mohammad Mirhosseini, and Ehsanollah Zeighami. "Numerical and experimental study on the behavior of drilled flange steel beam to CFT column connections." In Structures, vol. 28, pp. 726-740. Elsevier, 2020.

[125] Heidari, Peyman Shadman, Armin Aziminejad, A. S. Moghadam, and Mohammad Ali Jafari. "Evaluation of drilled flange connections with combined arrangements of holes and notches." Bulletin of Earthquake Engineering 18, no. 14 (2020): 6487-6532.

[126] Ting, L. C., N. E. Shanmugam, and S. L. Lee. "Box-column to I-beam connections with external stiffeners." Journal of Constructional Steel Research 18, no. 3 (1991): 209-226.

[127] Shin, Kyung-Jae, Young-Ju Kim, Young-Suk Oh, and Tae-Sup Moon. "Behavior of welded CFT column to H-beam connections with external stiffeners." Engineering Structures 26, no. 13 (2004): 1877-1887.

[128] Kang, Chang-Hoon, Kyung-Jae Shin, Young-Suk Oh, and Tae-Sup Moon. "Hysteresi behavior of CFT column to H-beam connections with external T-stiffeners and penetrated elements." Engineering structures 23, no. 9 (2001): 1194-1201.

[129] Tsavdaridis, Konstantinos Daniel, and Christopher Pilbin. "Finite element modelling of steel connections with web openings: aseismic design and progressive collapse." In The 7th European Conference on Steel and Composite Structures. Eurosteel 2014, 2014.

[130] Arasaratnam, P., K. S. Sivakumaran, and M. J. Tait. "True stress-true strain models for structural steel elements." ISRN Civil Engineering 2011 (2011).

[131] ANSYS Inc. ANSYS user guide, version 15.0.

[132] Uriz, Patxi. Towards earthquake resistant design of concentrically braced steel structures. University of California, Berkeley, 2005.

[133] Uriz, Patxi, Filip C. Filippou, and Stephen A. Mahin. "Model for cyclic inelastic buckling of steel braces." Journal of structural engineering 134, no. 4 (2008): 619-628.

[134] Santagati, S., D. Bolognini, and R. Nascimbene. "Strain life analysis at low-cycle fatigue on concentrically braced steel structures with RHS shape braces." Journal of earthquake engineering 16, no. sup1 (2012): 107-137.

[135] Lee, C. H., \& Kim, J. H. (2007). Seismic design of reduced beam section steel momen connections with bolted web attachment. Journal of Constructional Steel Research, 63(4), $522-531$.

[136] Zee, Howard L., and Jack P. Moehle. Behavior of interior and exterior flat plate connection subjected to inelastic load reversals. University of California, Earthquake Engineering Research Center, 1984.

[137] Benavent-Climent, A., X. Cahís, and J. M. Vico. "Interior wide beam-column connection in existing RC frames subjected to lateral earthquake loading." Bulletin of Earthquake Engineering 8, no. 2 (2010): 401-420.

[138] Shademan, Pouya, and Roohollah ahmady Jazany. "Study of seismic behavior of Drilled flange connection with slot hole."DOI: 10.22060/CEEJ.2018.14422.5652 